\title{
Tecnologias digitais na revista Veja: a construção de um futuro despotencializado
}

Edilson Calzeloto e José Luiz Aidar Prado

\section{Resumo}

0 artigo busca analisar como o enunciador de

Veja, a principal revista semanal brasileira, coloca em discurso o tema da tecnologia. 0 texto parte das seguintes hipóteses principais: a) em Veja predomina uma visão de mundo calcada no determinismo tecnológico; b) a tecnologia é discursivizada como uma estratégia para a construção de um futuro que, em síntese, tende a reproduzir as relações sociais do presente e que c) a tecnologia atua como despontencializadora das possibilidades de transformação social.

\section{Palavras-Chave}

Cibercultura. Tecnologia. Futuro. Jornalismo. Revista Veja.
Edilson Calzeloto I edcazeloto@yahoo.com.br Jornalista, radialista, mestre e doutor em Comunicação e Semiótica pela Pontifícia Universidade Católica de São Paulo (PUC/SP), professor do Programa de Pós-Graduação em Comunicação da Faculdade Cásper Líbero.

José Luiz Aidar Prado | zupraa@pq.cnpq.br Professor do Programa de Pós-Graduação em Comunicação e Semiótica da Pontifícia Universidade Católica de São Paulo (PUC/SP).

\section{Introdução}

Investigaremos neste artigo como o enunciador de Veja, a principal revista semanal brasileira, com tiragem média de 1 milhão de exemplares semanais, editada pelo Grupo Abril, coloca em discurso o tema da tecnologia. Nossa metodologia foi a análise discursiva a partir de Laclau, dividindo o corpus a partir dos pontos nodais, que engendram diferentes contratos de comunicação. 0 enfoque discursivo de Laclau considera que houve uma inversão de prioridades entre social e político, tendo este sido absorvido pelo outro, havendo a necessidade de se reverter tal processo. Sua teoria pós-fundacional da hegemonia visa tal reversão (LACLAU; MOUFFE, 1985; MARCHARD, 2008). A parte da política absorvida pelo social é aquela do dispositivo sistêmico de gestão, que regula o funcionamento social. Para Laclau não existe $a$ sociedade como um sistema totalizado, mas lutas discursivas específicas que buscam hegemonizar suas posições, minimizando diferenças. Os pontos nodais são produzidos cada vez que uma nova articulação produz uma totalização discursiva parcial e provisória, a 
partir de palavras de ordem que atuam como significantes vazios. Em Veja, a palavra de ordem "tecnologia digital" atua como um significante vazio em posição de ponto nodal, ao costurar, como veremos, concepções específicas de futuro, de criatividade, de inovação, de economia e de fins sociais a alcançar.

Analisar o discurso midiático sobre a tecnologia é uma forma de investigar os valores socialmente construídos que norteiam (sem determinar) 0 desenvolvimento e 0 aperfeiçoamento das tecnologias ou, em outros termos, interpretar a luta pela hegemonia na construção do sentido social da tecnologia que repercutirá concretamente nas formas do design tecnológico e nas apropriações dele realizadas. É necessário enfatizar que as "mídias" não produzem um discurso totalizante e são, elas próprias, palco de disputas entre sentidos concorrentes. Por esta razão, é importante analisar uma publicação relevante no cenário brasileiro, como Veja, cujos contratos de comunicação constroem uma "tendência dominante" no tratamento midiático das tecnologias digitais e, portanto, na construção de certa concepção de futuro. A mídia configurase como enunciadora de "mapas cognitivos", que constroem modalizações (receitas) indicando e induzindo formas específicas de produzir e interpretar os sentidos dos fenômenos sociais, 0 que as caracteriza como operadores semióticos: seu dizer sobre a tecnologia cria expectativas e difunde valores que serão incorporados aos objetos técnicos nos momentos do design e do uso.
Nosso primeiro passo metodológico consistiu em coletar todas as reportagens com tema "tecnologias digitais" e classificá-las a partir de seus contratos de comunicação, com respectivos pontos nodais, o que permitiu propor quatro grupos temáticos.

\section{0 s heróis da nova economia}

0 primeiro grupo temático traz narrativas sobre os heróis bilionários do mundo digital: Bill Gates, Mark Zuckerberg, Steve Jobs, Jerry Yang, Larry Ellison e o brasileiro Eduardo Saverin, entre outros. 0 traço comum dessas narrativas está na euforização da economia das tecnologias digitais construídas discursivamente a partir da atuação empreendedora, desafiadora e criativa desses agentes bilionários e na saga dessa própria construção, mostrada como um tremendo enriquecimento, que aliás é 0 valor supremo do enunciador. As palavras de ordem dessa discursivização são: "milionários.com", "fortuna na rede" (em "clique de midas", por exemplo), "epopeia empresarial", "empreendedorismo", "novidades tecnológicas e nova economia". A partir desses pontos nodais da invenção que produz bilhões e lucros bem maiores que os da velha economia, são postos os valores da narrativa, ao redor dos quais esses sujeitosheróis constroem seus mundos e os nossos. Na reportagem de 23/2/2000 (ed. 1637) “milion@rios. com", o enunciador explica o salto de valor que as empresas "ponto.com" apresentam em relação a seu patrimônio tradicional: 
[...] os serviços on-line mais valorizados, à luz das regras da economia tradicional, são apenas éter. São nada. São feitos de computadores comuns ligados a uma rede e recebem visitas diárias de pessoas que também possuem computadores. Não há propriamente patrimônio físico. Esses serviços vivem da esperança de que no dia seguinte voltarão a ser visitados por milhares ou milhões de pessoas. Neste momento tais abstrações valem dinheiro.

A perspectiva futura é de se ganhar muito dinheiro com a "revolução digital". Na reportagem de 30/5/2012, sobre a saga do brasileiro Eduardo Saverin, também bilionário, o enunciador informa onde ele investe seu dinheiro, sobre um fundo imagético de um céu azul cheio de nuvens.

Todas as reportagens sobre essas celebridades bilionárias tem como ponto nodal a quantidade de dinheiro acumulado na nova economia digital: "No Brasil a estimativa é que exista atualmente 1,3 bilhão de dólares prontos a ir para as mãos de jovens que se acham aptos a lançar um negócio on-line" (23/2/2000, ed. 1637).

Os agentes-heróis são homens poderosos, diferentes dos empresários da velha economia até no vestir, tendo traços de uma criatividade dosada em excesso. Sobre Jerry Yang, um dos fundadores do Yahoo!, a revista nota que é "difícil acreditar que esse garoto de ascendência asiática, míope, quase sempre metido num par de jeans e camisa quadriculada, seja 0 epicentro de uma revolução tecnológica e comercial tão profunda quanto a internet" (15/3/2000, ed.1640). Sobre Steve Jobs, criador da Apple, a revista destaca atributos pouco familiares ao tradicional padrão empresarial:
"Jobs não era excepcionalmente inteligente, mas era gênio, antena da raça, experimentador de sensações (usou LSD na juventude e peregrinou pela Índia)" (12/10/2011, ed. 2238).

Outro exemplo descreve Eduardo Saverin, que criou o Facebook ao lado de Mark Zuckerberg: "Saverin age como quem joga xadrez - tenta antever o que virá depois, em lances ora agressivos, ora cautelosos." Desistiu da cidadania americana para não pagar impostos, diz 0 enunciador, mas Saverin nega, afirmando que preferiu viver em Singapura. 0 enunciador 0 apresenta como tímido e reservado. Ao mesmo tempo que descreve traços, uns idiossincráticos, outros comuns, Veja passionaliza a apresentação heróica com uma humanidade carregada de ternura.

0 valor supremo, ao lado do empreendedorismo, é 0 dinheiro em termos de bilhões de dólares. Por que sempre 0 dinheiro? 0 enunciador responde a essa questão na reportagem sobre Larry Ellison (18/10/2000, ed. 1671), o criador da Oracle. Diz 0 enunciador logo no início da matéria que Ellison

[...] quer ganhar ainda mais dinheiro e ser o primeiro, à frente de Bill Gates. Não é tanto pelo dinheiro. Depois do primeiro bilhão, já não faz tanta diferença ter mais no terreno aquisitivo. 'Quando você conquista o primeiro bilhão, os carros ficam mais velozes, os aviões mais confortáveis e as mulheres a sua volta ficam com as pernas mais compridas'. A partir daí, a pessoa já comprou tudo o que os dólares permitem. [...] 0 primeiro bilhão virou 50 bilhões [...] sua fortuna pessoal beirou os 60 bilhões de dólares, encostando nos 68 bilhões de Bill Gates. Tudo isso faz sua aura tornar-se mais iluminada e in- 
trigante, especialmente quando o homem que ela ilumina é muito parecido com um roqueiro madurão que ainda se dá ares de rebelde.

Para Veja, os jovens empreendedores do universo digital devem servir como exemplo universal de competência e ousadia, multiplicando o gosto pela aventura do mercado em sua geração. 0 tom é dado por Eduardo Saverin, ao comentar a relevância do Facebook: "Espero que a história do Facebook, que teve início no quarto de uma república universitária, sirva de inspiração para que pessoas de todas as idades e todos os setores se aventurem pelo empreendedorismo e busquem seus sonhos". 0 futuro aqui é sinônimo de bilhões de dólares conseguidos com a invenção do objeto tecnológico.

\section{A nova economia}

Grande parte das narrativas se voltam, após situar os heróis-bilionários-celebridades, para a descrição da nova realidade das tecnologias digitais, apresentando o mapa cognitivo desse mundo: veja como é, saiba como funciona, aprenda e ganhe dinheiro com ele. A apresentação da atualidade digital visa instrumentalizar 0 enunciatário para o futuro. Desde 1995, Veja tem dedicado reportagens de capa ao tema das tecnologias digitais e seus correlatos. A primeira edição a lidar com 0 tema deu 0 tom que será seguido pelas demais reportagens, anunciando: "internet: a rede planetária em que você ainda vai se plugar" (Veja, 1/03/1995, ed. 1381). 0 enunciador não diz somente "0 que é" a internet: ele "modaliza" o leitor no sentido de um saber específico, ou seja, um modo de interpretar o "sentido" da rede e suas implicações para a construção de um devir tecnológico que já se apresenta como fato inescapável para todos. Para isso, apropria-se do discurso de "futurólogos" como Nicholas Negroponte, do Massachussets Institute of Technology (MIT) - apresentado como um cientista "profeta" -, que abre a matéria anunciando: "o futuro chegou". Ao lado de explicações técnicas cheias de metáforas (incluindo um pequeno "glossário" com termos usados no jargão das redes telemáticas), a revista busca dar "sentido" à internet. Esse "sentido" é, prioritariamente, utilitarista:

Mas afinal, para que serve a internet? Serve para que milhões de pessoas separadas por milhares de quilômetros conversem horas a fio teclando suas frases nos computadores e pagando o preço de uma ligação telefônica local. Serve para consultar um livro ou um documento em 2.000 bibliotecas que podem ser acessas a distância, 24 horas por dia [...] serve também para que pessoas com interesses comuns, como os ecologistas, os gays, os médicos ou os fanáticos por esportes, conversem com suas almas gêmeas espalhadas pelo mundo. Serve para que cientistas, separados no tempo e no espaço possam trabalhar em projetos comuns, compartilhando a mesma tela mas usando teclados diferentes, um deles em Paris, 0 outro em Nova York (Veja, 1/03/1995, ed. 1381, p. 49-50).

A novidade também é apresentada como uma nova forma de se fazer negócios e distribuir mercadorias:

Canções podem ser digitalizadas - como já são nos CDs musicais -, e assim, passeiam pela internet. Jornais inteiros são igualmente trans- 
formados em bits e postos à disposição dos assinantes. Dinheiro também pode trafegar como mensagem cibernética, na forma de números de cartão de crédito. Os bits são a maior riqueza deste fim de século, ou sua mais completa tradução (Veja, 1/03/1995, ed. 1381, p. 51).

A rede mundial é saudada como a mais importante transformação da economia capitalista contemporânea, impondo sua lógica para todo 0 setor produtivo. Já na edição 1632 (19/01/2000, "Nasce a nova economia", p. 98), a revista usa a fusão das empresas AOL e Time Warner para demarcar as transformações que estavam acontecendo no mercado mundial e afirma: "A fusão da A0L com a Time Warner é desconcertante porque marca o triunfo da internet, logo nos primeiros dias do século XXI, como o mais vigoroso motor da economia mundial". 0 tema da internet como "motor da economia mundial" será sempre retomado e retrabalhado em diversos ângulos:

Junto com a internet, estaria sendo criado também um novo modo de produção e de distribuição de riqueza completamente distinto das formas de fazer dinheiro conhecidas e aperfeiçoadas pela humanidade no decorrer do século que terminou (Veja, 19/01/2000, ed. 1632, p. 100).

A internet é construída, ao mesmo tempo, como uma nova fronteira para os negócios, como paradigma de atuação para as empresas privadas, para os trabalhadores e empreendedores individuais. A "nova economia" impõe às empresas estabelecidas a necessidade de uma completa reformulação de suas formas de gerenciamento, sob pena de sucumbirem em um cenário de competição acirrada e de rápidas transformações. Para marcar sua posição, a revista chega a noticiar especulações envolvendo empresas acionadas discursivamente por seu valor simbólico:

\begin{abstract}
A Ford Motors, cujo fundador Henry Ford foi 0 criador do moderno capitalismo nos anos 20, vem procurando se associar à mais emblemática empresa da era da internet, a Yahoo! 0 objetivo da associação é pouco claro, mas a empresa fabricante de automóveis descobriu que a internet é a menor distância entre ela e seus futuros clientes (Veja, 19/01/2000, ed. 1632, p. 103)
\end{abstract}

0 modelo de acumulação baseado na produção é questionado (ou está se tornando mais complexo) a partir das imposições trazidas pela nova economia. As empresas tradicionais estariam sendo forçadas a se adaptarem, sob pena de se tornarem inviáveis nesse futuro projetado. 0 enquadramento temático incide em torno do chamado "modelo de negócios": "Às vezes, é necessário mudar o modelo de negócio. A gravadora Trama, que vivia até 5 anos atrás da venda de CDs, resolveu colocar álbuns inteiros, de graça, na internet. Quem paga a conta são os patrocinadores" (12/8/2009, ed. 2125, p. 90).

0s agentes tecnológicos são os empreendedores criativos e concorrentes da rede, figurativizados nos donos-inventores: Gates, Ellison, Jobs, Yang. Há um antagonismo entre eles, que 0 enunciador constrói a partir da oposição Ellison X Gates (18/10/2000, ed. 1671), o primeiro imerso na internet e 0 segundo ainda baseado no modelo do computador pessoal. Para um, o futuro é a rede e para outro, não só. 
Outra oposição forte é Jobs X Gates, investindo a Apple em outros dispositivos além do computador pessoal. A pegada enunciadora dos contratos é sempre na direção da valorização da invenção e na aposta de descobrir o que 0 consumidor quer. 0s modos pelos quais aparecem tais imagens de futuro caracterizam o regime de visibilidade das tecnologias digitais, ou seja, a grande aventura do enriquecimento, do empreendedorismo, da vitória no mercado ao construir o futuro, a disputa por entender a direção "correta" (a que rende mais dinheiro) do investimento e da criação.

Para realizar-se, a nova economia ainda tem de enfrentar um antigo inimigo, presente desde os primórdios do pensamento liberal: o Estado. As formas de regulação pública são apresentadas pela revista como entraves ao florescimento da nova economia. Sobre a gestão estatal da internet em seus primórdios no Brasil (antes da privatização do sistema de telecomunicações), a revista afirma: "Sem alguns empresários, a Internet nem sequer existiria. É a típica contribuição das empresas que fornecem circuitos de acesso à rede. Já os governos não tem com que contribuir. Se não atrapalharem, serão de grande ajuda" (1/3/1995, ed. 1381, p. 57).

\section{0s gadgets mágicos}

Um desdobramento do grupo temático anterior traz os objetos mágicos da nova economia, em que 0 enunciador mostra que os novos programas de computador, os novos sites e os dispositivos como iPads e iPods transformam as relações dos "espectadores" e consumidores entre si e com 0 mundo. Na reportagem de 13/9/2006 (ed. 1973), o enunciador afirma que o Youtube está transformando "[...] a relação do espectador com o mundo da imagem. É uma revolução que marca o fim da TV como se conhecia até hoje". As redes de TV não concorrem em termos de ineditismo e variedade com o Youtube, porque diariamente milhões de usuários colocam novos vídeos no site. "A popularização dos canais pagos, no início dos anos 80, foi um primeiro passo para satisfazer esse desejo. 0 processo continua se aprofundando, com a chegada de tecnologias que dão ao espectador a oportunidade de ver TV quando e onde ele quiser". É o tema da liberdade de expressão e de seleção do espectador, da TV personalizada e mais além, para "[...] as comunidades para quem gosta de ver, comentar e fazer vídeos".

\section{Outras reportagens tematizam essas} transformações no mundo da cultura e da comunicação, caracterizando um mapa cognitivo desse novo mundo que se abria. Na reportagem de 5/5/2010 (ed. 2163), o enunciador fala de uma comunicação-tradução universal do Google tradutor. "Por trás do Google está o conhecimento acumulado de inteligência artificial [...] A cada língua colocada à disposição na internet, surgem chances de aumentar a troca de ideias e diminuir as diferenças culturais". 0 enunciador lista uma série de benefícios com o programa tradutor, desde a leitura por parte de empresários de contratos 
que fazem com o exterior, até facilitação da leitura de textos em centenas de línguas por turistas, técnicos, investidores, estudantes etc.

Na reportagem de 23/6/2010 (ed. 2170), 0 enunciador fala sobre a fofoca digital, trazida pelo Twitter. As maledicências ou fofocas sempre circularam pelo mundo, mas a novidade agora está na internet, na fofoca digital. 0 caso que motiva a matéria foi a twitagem "Cala a boca Galvão". 0 Twitter é apresentado em várias dimensões, inclusive da política iraniana, em que a população recorreu a ele para "[...] denunciar fraudes na apuração (eleitoral), organizar protestos nas ruas de Teerã e divulgar imagens da repressão policial". 0 enunciador cita Tim Hwang, do Web Ecology Project, centro de estudos de Harvard: "Numa rede como essa, a voz das pessoas comuns ganha enfim dimensão pública”. 0 mundo empresarial, diz 0 enunciador, também abraça 0 Twitter.

\section{0 "espaço de risco"}

Do ponto de vista da apropriação social da internet, para além das questões econômicas, Veja constrói o mundo digital em geral e a internet em particular como um "espaço de risco". Em várias reportagens de capa, a revista busca mostrar que as novas práticas culturais que emergem no contexto das redes são potencialmente danosas aos valores sociais tradicionais, como a família e, é claro, a propriedade, principalmente por conta de uma certa "liberdade de expressão descontrolada".
Assim, o contrato de comunicação de Veja dirigese a um enunciatário que, a princípio, partilha destes valores, considerados "tradicionais" da sociedade brasileira e fortemente identificados com as classes médias do país.

$$
\begin{aligned}
& \text { A família mononuclear e o casamento são } \\
& \text { exemplos dessas modalizações. Em uma } \\
& \text { reportagem de capa que trata do tema da } \\
& \text { infidelidade (25/01/2006, ed. 1940, p. } 77) \text {, a revista } \\
& \text { relaciona a troca de mensagens eletrônicas e a } \\
& \text { infidelidade conjugal: }
\end{aligned}
$$

$$
\begin{aligned}
& \text { A internet criou uma nova maneira de ser infiel: } \\
& \text { começa com mensagens, evolui confidências, } \\
& \text { logo entra no reino das fantasias sexuais. Quan- } \\
& \text { do menos se espera, o marido ou a mulher já } \\
& \text { estão teclando sem parar com um desconhe- } \\
& \text { cido. Mesmo que nunca se transfira para a vida } \\
& \text { real, a traição machuca do mesmo jeito. }
\end{aligned}
$$

0 risco a que a família mononuclear está exposta também aparece como um ataque à infância. Com a imagem de uma criança assustada, iluminada apenas pela luz fria de uma tela de computador, a revista traz a manchete: "Perigo da tela como proteger seu filho dos riscos da internet" (18/7/2007, ed. 2017). 0 enunciador Veja (p. 87) adverte: "Nesta reportagem, vamos falar sobre o lado escuro da força na rede, realidade que nenhum adulto responsável por uma criança conectada pode se permitir ignorar". Pedofilia, fraudes, sequestros: as crianças on-line estariam submetidas a uma série de danos proporcionados pela forma ingênua com que são expostas pela comunicação digital. A psicóloga Rosely Sayão 
afirma: "largar uma criança pequena sozinha na internet é mais perigoso do que deixá-la sozinha na Praça da Sé, no centro de São Paulo. Na rua, ela sabe que corre o risco de ser assaltada ou sequestrada e fica mais atenta. No computador, ela se sente segura porque está em casa" (18/7/2007, ed. 2017, p. 87).

Contra os "riscos" da rede, a revista recomenda a autoridade dos pais: "Não é só para orientar que os adultos responsáveis tem que saber mexer no computador. É para fiscalizar também, vigiar mesmo, clara e abertamente, com a maior naturalidade, sem 0 autoritarismo e sem medo de exercer a obrigação da autoridade" (ed. 2017, p. 88).

Outra matéria que constrói a internet como um "espaço de risco" é a intitulada "Mouse ao Alto" (20/5/2009, ed. 2113, p. 87-96). 0 objeto construído pela publicação são os "crimes cibernéticos", principalmente as fraudes mercantis de todas as naturezas. Nesse campo, a revista esforça-se por apontar o risco inerente às transações comerciais eletrônicas mantendo, ao mesmo tempo, a credibilidade no sistema:

No Brasil, o volume de notificações relacionadas a fraudes, furtos, vírus destruidores, invasões e tentativas de invasão de computador quadruplicou em cinco anos. No ranking dos crimes eletrônicos que mais crescem, o que atenta contra 0 patrimônio ocupa 0 primeiro lugar: só os programas destinados a invadir contas bancárias infectam 195 computadores por hora no país. Isso significa que a rede virtual é um campo minado e que usá-la para fazer compras ou transações bancárias se tornou um comportamento de risco? Absolutamente, não. (Veja, 20/5/2009, ed. 2113, p. 88-90).

0 problema da insegurança é creditado à "pouca familiaridade" do brasileiro com a rede e ao uso intensivo de softwares piratas que, segundo Veja (p. 90), "[...] tornam os computadores mais vulneráveis aos ataques já que, ao contrário dos programas legais, não são atualizados pelos fabricantes à medida em que os criminosos inventam novas formas de infiltração" .

A revista destaca ainda os crimes de difamação e calúnia e os falsos sites de compra, que recebem o pagamento, mas não entregam as mercadorias. A responsabilidade, nesses casos, recai sobre a legislação: "a lei brasileira está vários passos atrás dos criminosos virtuais. Os delitos cometidos pela rede - salvo exceções como a divulgação de pornografia infantil - não são contemplados no rol de crimes brasileiros" (p. 94). Ao final da matéria, a revista enuncia sua síntese: "Se navegar é preciso, prevenir-se também é".

Finalmente, o enunciador fala de outro risco na reportagem sobre Julian Assange, criador do Wikileaks (15/12/2010, ed. 2195), em que se mostra o lado negro da internet e do mundo digital, aquele que põe em risco a democracia, pelo menos como 0 enunciador a entende. Assange é dito inimigo do Estado. 0 Wikileaks havia divulgado 250 mil mensagens entre Washington e embaixadas norte-americanas. 0 enunciador chama de guerra cibernética o que houve em 
seguida, com ataques hacker de uma série de instituições em represália à prisão de Assange. Veja chama esse ataques de "vandalismo". Ele, tornado subitamente celebridade, estava preso na Inglaterra, enquanto a Suécia o investigava por estupro. Diz o enunciador:

[...] para uns, Assange é o mártir da liberdade na internet que adotou uma vida nômade, fugindo de perseguidores, para dedicar-se à revelação dos segredos sujos de governos e corporações e inaugurar uma era de megatransparência. Para outros, é um anarquista que viola segredos com métodos espúrios e usa a rede mundial de computadores para sabotar as relações pacíficas entre países. Assange talvez não seja o herói nem 0 vilão da alegoria medieval do bem e do mal. Mas certamente é, nesse momento, o primeiro inimigo público do estado na era digital - ou dos estados, dos poderes constituídos, do status quo.

A narrativa é descritiva da guerra entre os hackers e as instituições que atacaram o Wikileaks. Em relação aos hackers que apoiaram o Wikileaks, afirma o enunciador:

Em manifestos, esses hackers dizem que sua missão é zelar pela liberdade de expressão e atacar quem a ameace. São contra governos e corporações, que identificam como inimigos da liberdade na rede. A adesão dos hackivistas do Anonymous foi um desastre para o Wikileaks. 0 grupo reúne jovens que promovem uma atividade ilegal. São vândalos da internet. Dizem atuar em nome da liberdade e da liberdade e da transparência, e talvez até estejam cheios de boas intenções, mas seus métodos são deploráveis.

Numa legenda da foto de Obama, o enunciador afirma: "0 presidente Obama, que quer processar Assange: falta encontrar 0 instrumento legal.
Afinal, isto aqui não é a China”. Após narrar algumas das informações "obscenas" (ŽIŽEK, 1991) que vieram a público pelo Wikileaks, o enunciador termina a matéria afirmando: "Esses detalhes - que se perpetuarão para 0 trabalho de historiadores - só vieram a público porque um pedaço do mundo é democrático. E respeita a liberdade de expressão".

\section{0 mundo digital em Veja}

Façamos neste ponto a síntese de nossas descobertas. 0 enunciador de Veja constrói 0 mundo digital a partir de quatro grandes grupos temáticos, caracterizando a tecnologia a partir de regimes de interação e visibilidade variados:

a) Os novos heróis: a revista euforiza neste grupo temático o empreendedor a partir do ponto nodal "empreendedorismo na nova economia", fazendo desfilar os novos "heróis" do mercado digital, que estariam desbravando esse novo mercado e impondo-se como modelos de gestão.

Nas capas figuram esses heróis do mundo da informática, tais como Gates, Ellison, Jobs, Yang, Zuckerberg etc. Neste grupo, a tecnologia é discursivizada e tornada visível a partir do empreendedorismo e da inovação personalizada nos actantes-heróis da nova economia digital.

b) A nova economia: neste grupo, as reportagens de capa apresentam as 
grandes empresas bilionárias da rede, com ênfase nas cifras envolvidas que elas movimentam. 0 ponto nodal aqui é "inovação e grandes lucros". Veja opera uma polarização entre 0 "velho" e 0 "novo" mundo da economia. Nesse caso, as novas empresas são as que surgem operando no mercado das tecnologias digitais e são caracterizadas por virtudes como "agilidade", "flexibilidade", "ousadia" e "inovação".

c) Os gadgets mágicos: neste grupo, desdobramento do anterior, são apresentados novos programas de computador, sites revolucionários, objetos mágicos como iPod e iPads, novas tecnologias de educação a partir de site de vídeos etc. 0 ponto nodal deste grupo é a tecnologia como "objeto mágico", que são os actantes principais das narrativas desse grupo temático.

\section{d) 0 "lugar de risco": 0 universo das} tecnologias também é compreendido como um desafio à sociedade. As novas práticas culturais que emergiram a partir da disseminação do computador e das redes telemáticas estariam colocando em risco valores tradicionais como a proteção à infância, a família mononuclear, a democracia e a competência educacional. 0 ponto nodal deste grupo é "risco das novas tecnologias".
Ao articular esses temas, em primeiro lugar, Veja reitera o "valor supremo" do enriquecimento econômico. A combinação de tecnologias digitais e mercado é tematizada, ao mesmo tempo, como a abertura de oportunidades para o sucesso aos novos empreendedores e como uma imposição fatal aos empresários tradicionais da economia industrial. A tecnologia atua no paradigma determinista, criando as condições objetivas para transformações relevantes do capitalismo que Veja tematiza como a "nova economia". 0 futuro pertence aos jovens empreendedores dinâmicos, criativos, de comportamento idiossincrático, representados pelos novos "heróis", como Gates, Jobs e Zuckerberg. A inovação permanente é 0 único modo de acumulação das novas fortunas: valores tradicionais do capitalismo, como 0 zelo diligente e 0 cálculo, são substituídos pelo ímpeto e pela "genialidade" (a grande "marca" dos heróis da nova economia). 0 sucesso não é mais construído: ele "surge" a partir de uma combinação de talento inato, oportunismo e intuição. A posição que deve ser ocupada pelos leigos é a de usuários, encantados e agradecidos pelas grandes inovações que surgem das pranchetas dos "gênios" da raça.

Nesse cenário, o Estado e a regulação pública ainda são empecilhos à "genialidade" dos empreendedores. Veja aponta uma incompatibilidade entre 0 poder estatal, tido como lento e burocrático, e a dinamicidade exigida pelo novo contexto da economia digital. 0 Estado aparece como um peso que atua contra a velocidade globalizada dos negócios. 
Mas, o mundo digital é também um "espaço de risco". Ele ameaça fortunas construídas na "velha economia" e os valores sociais mais tradicionais, como a família monogâmica e a propriedade privada. De acordo com a revista, o risco, no entanto, não está nos aparatos tecnológicos, mas nas instrumentalizações secundárias (FEENBERG, 2002), ou seja, no uso concreto e cotidiano dos objetos. 0 risco surge quando o "usuário" deixa sua posição de consumidor bem comportado e utiliza as tecnologias redentoras para fins não previstos, como 0 adultério, a pedofilia e 0 crime. Nesses casos, a "autoridade" deve intervir, seja na forma da repressão estatal, da vigilância atenta dos pais ou no aconselhamento dos "profissionais da alma" (psicólogos, psiquiatras, terapeutas etc.), no sentido de corrigir as "distorções" do futuro tecnológico imaginário.

No futuro de Veja, o mundo digital é uma prótese eletrônica do mercado em que a participação ativa dos "usuários" deve ser vista com suspeição.

\section{Qual tecnologia?}

Nesse item, interessa-nos focar não nos regimes de interação e de visibilidade instalados pelo enunciador (que vimos nos itens anteriores), mas no campo de invisibilidades que resulta de uma análise mais ampla do tema. Colocaremos então esta concepção de tecnologia que 0 enunciador Veja projeta em seus contratos de comunicação em confronto com uma visão alternativa, que traremos a partir da obra do filósofo Andrew Feenberg (2002). Em sua Teoria Crítica da Tecnologia, 0 autor ressalta 0 caráter radicalmente social da dinâmica tecnológica. Construindo uma via analítica que ultrapassa tanto o instrumentalismo quanto o determinismo, que marcam os modos ocidentais de pensar os processos tecnológicos, Feenberg constrói uma visão em que a tecnologia surge como momento privilegiado do social. 0 objeto técnico cristaliza uma forma específica de hegemonia, ao mesmo tempo em que se abre e se transforma a partir do antagonismo entre interesses e demandas. Esse antagonismo aparece em Veja apenas a partir do confronto entre empresas que querem lucrar mais, como vimos, por exemplo, nas disputas entre Microsoft, Oracle e Apple, ditadas, portanto, por interesses econômicos e resolvidos a partir da inovação tecnológica. Em Feenberg (2002) esse antagonismo é social, envolvendo distintos valores e concepções de mundo e mobilizando os diferentes grupos que produzem e se apropriam cotidianamente dos aparatos tecnológicos. Para Feenberg, todo e qualquer objeto técnico insere-se na vida cotidiana a partir de um duplo movimento. De um lado, ele é a materialização de valores, visões de mundo e intenções mais ou menos explícitas ou conscientes de seus "criadores" (especialistas em diversas áreas do conhecimento responsáveis pela produção, em qualquer escala, dos objetos técnicos). Ao tomarem certas decisões sobre o design de seus produtos, esses "criadores" estão, de alguma forma, "codificando" suas 
crenças e valores em objetos. A tecnologia incorpora, assim, certos modos de conceber o mundo, uma vez que as escolhas do projeto são contingentes: cada tecnologia é 0 resultado de um conjunto de opções entre muitos outros possíveis. A essa codificação de valores no design tecnológico operada por um conjunto de especialistas, Feenberg denomina "instrumentalização primária".

No entanto, uma vez que o objeto técnico é criado, ele passa a existir no mundo social e, portanto, passa a ser um elemento ativo do antagonismo entre discursos. Isso significa que 0 "sentido" de toda tecnologia passa a ser disputado entre grupos antagônicos, decorrendo daí toda uma série de apropriações particulares e ressignificações que se produzem a partir do uso concreto desses objetos. A essa abertura do objeto técnico para a ressignificação produzida pelo uso concreto, Feenberg dá o nome de "instrumentalização secundária".

Em uma sociedade capitalista na qual a grande maioria dos objetos técnicos é produzida a partir da "forma-mercadoria", ocorre frequentemente um fenômeno de realimentação: na busca pelo lucro, usos que não foram previstos ou que nem eram desejados em uma primeira versão do objeto técnico são incorporados em versões subsequentes, ou seja, a instrumentalização secundária tende a guiar a instrumentalização primária, desde que ela não entre em conflito aberto e incontornável com os interesses dos "criadores".
Ao superar a visão meramente instrumental e/ou determinista da dinâmica tecnológica, associando-a ao antagonismo social como disputa entre valores e visões de mundo, Feenberg abre a possibilidade de intepretar a tecnologia a partir da perspectiva de sua inserção em "cadeias de equivalência" (LACLAU; MOUFFE, 1985). Como realidade semiótica, o objeto técnico é elemento constituinte de um determinado campo discursivo, operando-se aí certas articulações. Isso equivale a dizer que ocorre no social, inevitavelmente, uma disputa pelo sentido da tecnologia e que, graças à realimentação constante entre as instrumentalizações primária e secundária, essa disputa termina por interferir e influenciar a própria dinâmica tecnológica. 0 sentido socialmente produzido da tecnologia é um fator relevante no desenvolvimento dos próprios objetos técnicos. A hipótese que sustentamos é que inovações, invenções, aperfeiçoamentos e qualquer forma assumida pela dinâmica tecnológica são "moduladas" pelas expectativas em relação ao sentido das tecnologias e que essas expectativas são produzidas por estratégias discursivas que conformam o social.

Constitui-se, assim, um imaginário tecnológico, com efeitos absolutamente concretos sobre as escolhas tecnológicas que serão realizadas tanto pelos "criadores" como pelos "usuários". Essas escolhas, no discurso construído pelo enunciador de Veja, apresentam um "viés": são sempre decisões que se pautam por critérios de eficiência econômica. A atividade social, política, 
colaborativa e não mercantil são inseridas apenas marginalmente no mapa cognitivo proposto pela revista na "descrição" da internet e das tecnologias digitais. Projetos emancipatórios e distintos da lógica de acumulação financeira são interditados e não constam entre os usos possíveis da rede. Um bom indicativo deste "não dito" é a ausência quase absoluta de referências ao movimento pelo software livre ou ao sistema operacional Linux.

\section{Tecnologias digitais e concepção do futuro}

Em sua arqueologia histórica das mídias digitais, intitulada Futuros imaginários, 0 cientista político inglês Richard Barbrook (2009, p. 339) afirma que "[...] aqueles que esquecem 0 futuro estão condenados a repeti-lo". Para 0 autor, a criação de imagens e utopias futuristas (sociais ou tecnológicas) não é um exercício de ficção ou uma forma de profecia: é um ato político pelo qual grupos sociais são capazes de dirigir esforços e recursos públicos e privados na direção de certos interesses específicos. A "colonização do futuro" é uma estratégia discursiva que restringe as possibilidades das escolhas presentes pela apresentação do devir como direção unívoca, como se o futuro estivesse, desde sempre, inscrito no presente.

Quais são as condições a partir das quais essa apropriação de futuro se torna possível? Se é possível afirmar a abertura irredutível do futuro, como faz Barbrook, não parece viável crer em uma total imponderabilidade, como se o social pudesse ser conformado pelo simples exercício da vontade. É correto afirmar que "nós somos os criadores das coisas que virão" (BARBR00K, 2009, p. 384), mas apenas sob a condição de reconhecer que não criamos essas coisas ex nihilo: é no mundo social presente que se encontram os elementos capazes de construir visões de futuros imaginários alternativos. Nem determinação simplista, nem abertura radical: o presente é palco de conflitos dos quais podem resultar certas construções sobre os futuros possíveis.

Nesses conflitos, 0 discurso ${ }^{1}$ é, talvez, 0 elemento estratégico mais relevante. Se todo dizer é uma ação (AUSTIN, 1970), dizer sobre o futuro é construí-lo simbolicamente. No mundo social, as visões alternativas de futuro chocam-se e complementam-se de maneira a constituir um campo discursivo no qual o sentido das falas e dos objetos busca direcionar esforços e recursos que permitam a realização de certos valores e a instituição de certas relações sociais. Constituem-se articulações em torno de cadeias de equivalência (LACLAU; MOUFFE, 1985) que visam à construção de um futuro imaginário hegemônico, como uma "profecia autorrealizável".

Trata-se, portanto, de reconhecer no social uma luta discursiva no presente pela construção de futuros alternativos. Porém, os discursos e seus efeitos não são socialmente distribuídos de modo igualitário. A presença dos meios de comunicação 
hegemônicos, com fortes interesses, mais ou menos relevantes de acordo com o contexto social e cultural em que atuam, é um fator de extrema importância no que tange aos conflitos sobre o futuro. Ao construir seus mapas cognitivos modalizadores a mídia atua pela "naturalização" de certas concepções do futuro, ou seja, inscreve 0 amanhã no hoje, apresentando 0 devir como direção unívoca e consumada. Os enunciadores midiáticos constroem, portanto, regimes de visibilidade no presente, modalizando certas direções privilegiadas para que os leitores possam entender e situar-se no mundo atual, visando à consecução de um futuro, individual e coletivo, baseados em valores projetados em imaginários de consumo: cada um tem de ter objetos carregados de força simbólica, mapas simbólicos localizadores que direcionam para o sucesso, a felicidade, pensados ao modo individual. Cada vez mais os aparatos tecnológicos constituem, em si, discursos sobre 0 futuro e sobre o modo como 0 social tende a se organizar no campo da produção, do consumo e da subjetividade. Tecnologias podem ser entendidas, ao mesmo tempo, como o suporte material de práticas sociais e como refrações destas mesmas práticas. 0s discursos que circunscrevem o uso das tecnologias estão acoplados a discursos modalizadores de valores dos usuários, que afirmam como os sujeitos devem agir no social, quais devem ser os objetivos válidos e quais são as práticas culturais relevantes. $0 \mathrm{~s}$ futuros imaginários aparecem inscritos nas estratégias comunicacionais de implantação e circulação das tecnologias e nos sentidos que elas produzem. Como vimos, em Veja não se constrói um futuro aberto, a partir das contradições e antagonismos do atual mundo das tecnologias digitais.

\section{Conclusão}

No mundo contemporâneo, a inovação tecnológica não implica apenas na busca pela eficiência ou pela comunidade; ela é uma forma cada vez mais importante de construir o futuro, uma vez que os objetos técnicos contém, em si, valores e possibilidades de relações sociais. Não se trata, no entanto, de endossar a velha cantilena do determinismo tecnológico que vê, em uma suposta "essência da técnica" (HEIDEGGER, 2002) 0 destino inescapável da humanidade. 0 fenômeno técnico é ambíguo e sujeito a disputas, 0 que, em uma sociedade na qual o cotidiano é cada vez mais vivido com a interferência das tecnologias digitais, significa dizer que o sentido da tecnologia se tornou um espaço privilegiado para as disputas entre interesses distintos que constituem o social.

Sendo assim, os discursos que se formam em torno da tecnologia tornam-se fundamentais para a tomada de decisões de produção e de uso dos objetos tecnológicos, com efeitos imediatos na construção de um "futuro imaginário". 0 modo como a mídia apresenta o futuro tecnológico é um passo performativo para criar o futuro que o enunciador apresenta em suas narrativas axiológicas. Em Veja, como vimos, esse futuro 
é uma "utopia tecnoneoliberal": as tecnologias

digitais constroem uma nova configuração

do capitalismo, livre do peso das amarras do

sistema industrial, em que a "genialidade"

de empreendedores ousados e criativos é

sempre recompensada com um enriquecimento

assombroso, ainda que instável. 0 Estado, sempre

a dever melhor atuação e desqualificado para

participar deste cenário, atuaria apenas como

um regulador dos comportamentos "desviantes"

que ameaçam o livre fluxo do dinheiro, como 0

adultério, a pedofilia e os "crimes cibernéticos".

\section{Referências}

ASSANGE, J. et al. Cypherpunks: liberdade e o futuro da internet. São Paulo: Boitempo, 2013.

AUSTIN, J. L. How to do things with words. Oxford: Oxford University Press, 1962.

BADIOU, A. 0 ser e o evento. Rio de Janeiro: Zahar: UFRJ, 1996.

BARBROOK, R. Futuros imaginários: das máquinas pensantes à aldeia global. São Paulo: Peirópolis, 2009.

FEENBERG, A. Transforming Technology. New York: Oxford University Press, 2002. Edição eletrônica.

HEIDEGGER, M. A questão da técnica. In:

HEIDEGGER, M. Ensaios e conferências. Petrópolis, RJ: Vozes, 2002.

LACLAU, E.; MOUFFE, C. Hegemony and social strategy. London: Verso, 1985.

MARCHARD, 0. Laclau. Buenos Aires: Fondo de Cultura Económica, 2008.

ŽIŽEK, S. Hegel com Lacan: 0 mais sublime dos histéricos. Rio de Janeiro: Zahar, 1991. 

Veja magazine: construction of a non-potentiated future
Digital technologies in

\section{Tecnologías digitales en la revista Veja: construyendo un futuro despotencializado}

\section{Abstract}

The paper analyzes how the enunciator of Veja, Brazil's leading weekly magazine, places in speech the issue of technology. The text uses the following main assumptions: a) in Veja predominates a $n$ world vision grounded in technological determinism b) technology is placed in speech as a strategy for building a future that, in short, tends to reproduce actual social relations; c) technology acts to decrease the power of possibles social transformations. The research shows clear evidence in order to confirm the hypothesis. In fact, Veja builds an apologetic view of technological development that prefigures a deterministic picture of the future unfolding as a present were "the event", understood as Alain Badiou, is impossible. The Discourse Analysis , focusing on two thematic moments , points to two key trends: a) colonization of the future : technological future is built in cover stories (1968-2010) to legitimize hegemonic relations "encoded" (Feenberg) in technological devices,

b) disempowerment of the event: the foreshadowed vision of the future "frezzes" unpredictability of the present, that could engender political transformations , by operating a suture of the nodal point (Laclau), which could have disruptive effects on the order of capital . Thus, it is concluded that the possible break point represented by the potential of the technology is converted in to "quilting point" (Žižek), from which the discourse of technological determinism permanently reconstructs the social logic of Capital. Article drives, as the theoretical framework, recent post-structuralist Discourse Analysis (Laclau), Philosophy of the Event (Badiou) Theory and Criticism of technology (Feenberg) trends.

\section{Keywords}

Cyberculture. Technology. Future. Weekly Journalism. Veja Magazine.

\section{Resumen}

Este artículo busca analizar de qué manera el enunciador de la principal revista semanal brasileña, Veja, pone en discurso el tema de la tecnología. El trabajo parte de algunas hipótesis, las principales se exponen a continuación: a) en Veja predomina una visión del mundo fundamentada en el determinismo tecnológico; b) la tecnología es puesta en discurso como una estrategia para la construcción de un futuro que, en síntesis, tiende a reproducir las relaciones sociales del presente; y por último, c) la tecnología actúa como despotencializadora de las posibilidades de transformación social. La investigación da indicios suficientes para confirmar las hipótesis, de hecho, Veja construye una visión apologética del desarrollo tecnológico que prefigura una imagen determinista del futuro como un despliegue del presente. El análisis discursivo, que ha incidido en dos momentos temáticos, señala dos tendencias principales: a) la colonización del futuro: el futuro tecnológico es construido en los reportajes de la portada de la revista (1968-2010) de forma que legitima las relaciones hegemónicas codificadas (Feenberg) en los aparatos tecnológicos; b) la despontencialización del acontecimiento: la visión preconfigurada del futuro congela la imprevisibilidad/casualidad de un presente que podría gestar transformaciones políticas, operando una sutura en el lugar del punto nodal (Laclau) que podría tener efectos disruptivos en el orden del capital. Se concluye que el punto de una ruptura posible, representado por el potencial de la tecnología, se convierte en el "punto de taponamiento" (Žižek), a partir del cual el discurso del determinismo tecnológico reconstruye permanentemente lo social dentro de la lógica del Capital. El artículo acciona, como referencias teóricas, las recientes tendencias posestructuralistas del Análisis del discurso (Laclau) y de la Teoría Crítica de la Tecnología (Feenberg).

\section{Palabras-Clave}

Cibercultura. Tecnología. Futuro. Revista Semanal. Periodismo. Veja. 


\section{Expediente}

A revista E-Compós é a publicação científica em formato eletrônico da Associação Nacional dos Programas de Pós-Graduação em Comunicação (Compós). Lançada em 2004, tem como principal finalidade difundir a produção acadêmica de pesquisadores da área de Comunicação, inseridos em instituições do Brasil e do exterior.

\section{E-COMPÓS I www.e-compos.org.br I E-ISSN 1808-2599}

Revista da Associação Nacional dos Programas

de Pós-Graduação em Comunicacão.

Brasília, v.17, n.1, jan./abri. 2014.

A identificação das edições, a partir de 2008

passa a ser volume anual com três números.

\section{CONSELHO EDITORIAL}

Afonso Albuquerque, Universidade Federal Fluminense, Brasil Alberto Carlos Augusto Klein, Universidade Estadual de Londrina, Brasil Alex Fernando Teixeira Primo, Universidade Federal do Rio Grande do Sul, Brasil Ana Carolina Damboriarena Escosteguy, Pontifícia Universidade Católica do Rio Grande do Sul, Brasi

Ana Gruszynski, Universidade Federal do Rio Grande do Sul, Brasil Ana Silvia Lopes Davi Médola, Universidade Estadual Paulista, Brasil André Luiz Martins Lemos, Universidade Federal da Bahia, Brasi Ângela Freire Prysthon, Universidade Federal de Pernambuco, Brasil Antônio Fausto Neto, Universidade do Vale do Rio dos Sinos, Brasil Antonio Carlos Hohlfeldt, Pontifícia Universidade Católica do Rio Grande do Sul, Brasil Antonio Roberto Chiachiri Filho, Faculdade Cásper Líbero, Brasi Arlindo Ribeiro Machado, Universidade de São Paulo, Brasil Arthur Autran Franco de Sá Neto, Universidade Federal de São Carlos, Brasil Benjamim Picado, Universidade Federal Fluminense, Brasil César Geraldo Guimarães, Universidade Federal de Minas Gerais, Brasil Cristiane Freitas Gutfreind, Pontifícia Universidade Católica do Rio Grande do Sul, Brasil Denilson Lopes, Universidade Federal do Rio de Janeiro, Brasil Denize Correa Araujo, Universidade Tuiuti do Paraná, Brasi Edilson Cazeloto, Universidade Paulista , Brasil

Eduardo Vicente, Universidade de São Paulo, Brasil Eneus Trindade, Universidade de São Paulo, Brasil Erick Felinto de Oliveira, Universidade do Estado do Rio de Janeiro, Brasi Florence Dravet, Universidade Católica de Brasília, Brasil Gelson Santana, Universidade Anhembi/Morumbi, Brasi Gilson Vieira Monteiro, Universidade Federal do Amazonas, Brasil Gislene da Silva, Universidade Federal de Santa Catarina, Brasil Guillermo Orozco Gómez, Universidad de Guadalajara Gustavo Daudt Fischer, Universidade do Vale do Rio dos Sinos, Brasil Hector Ospina, Universidad de Manizales, Colômbia Herom Vargas, Universidade Municipal de São Caetano do Sul, Brasil Ieda Tucherman, Universidade Federal do Rio de Janeiro, Brasil Inês Vitorino, Universidade Federal do Ceará, Brasil Janice Caiafa, Universidade Federal do Rio de Janeiro, Brasil Jay David Bolter, Georgia Institute of Technology Jeder Silveira Janotti Junior, Universidade Federal de Pernambuco, Brasi João Freire Filho, Universidade Federal do Rio de Janeiro, Brasil John DH Downing, University of Texas at Austin, Estados Unidos
José Afonso da Silva Junior, Universidade Federal de Pernambuco, Brasil José Carlos Rodrigues, Pontifícia Universidade Católica do Rio de Janeiro, Brasil José Luiz Aidar Prado, Pontifícia Universidade Católica de São Paulo, Brasil José Luiz Warren Jardim Gomes Braga, Universidade do Vale do Rio dos Sinos, Brasil Juremir Machado da Silva, Pontifícia Universidade Católica do Rio Grande do Sul, Brasil Laan Mendes Barros, Universidade Metodista de São Paulo, Brasi Lance Strate, Fordham University, USA, Estados Unidos Lorraine Leu, University of Bristol, Grã-Bretanha Lucia Leão, Pontifícia Universidade Católica de São Paulo, Brasil Luciana Panke, Universidade Federal do Paraná, Brasil Luiz Claudio Martino, Universidade de Brasília, Brasil Malena Segura Contrera, Universidade Paulista, Brasil Márcio de Vasconcellos Serelle, Pontifícia Universidade Católica de Minas Gerais, Brasil Maria Aparecida Baccega, Universidade de São Paulo e Escola Superior de Propaganda e Marketing, Brasil Maria das Graças Pinto Coelho, Universidade Federal do Rio Grande do Norte, Brasil Maria Immacolata Vassallo de Lopes, Universidade de São Paulo, Brasil Maria Luiza Martins de Mendonça, Universidade Federal de Goiás, Brasil Mauro de Souza Ventura, Universidade Estadual Paulista, Brasil Mauro Pereira Porto, Tulane University, Estados Unidos Nilda Aparecida Jacks, Universidade Federal do Rio Grande do Sul, Brasil Paulo Roberto Gibaldi Vaz, Universidade Federal do Rio de Janeiro, Brasil Potiguara Mendes Silveira Jr, Universidade Federal de Juiz de Fora, Brasil Renato Cordeiro Gomes, Pontifícia Universidade Católica do Rio de Janeiro, Brasil Robert K Logan, University of Toronto, Canadá

Ronaldo George Helal, Universidade do Estado do Rio de Janeiro, Brasil Rosana de Lima Soares, Universidade de São Paulo, Brasil Rose Melo Rocha, Escola Superior de Propaganda e Marketing, Brasil Rossana Reguillo, Instituto de Estudos Superiores do Ocidente, Mexico Rousiley Celi Moreira Maia, Universidade Federal de Minas Gerais, Brasi Sebastião Carlos de Morais Squirra, Universidade Metodista de São Paulo, Brasil Sebastião Guilherme Albano da Costa, Universidade Federal do Rio Grande do Norte, Brasil

Simone Maria Andrade Pereira de Sá, Universidade Federal Fluminense, Brasi Tiago Quiroga Fausto Neto, Universidade de Brasília, Brasil Suzete Venturelli, Universidade de Brasília, Brasil Valerio Fuenzalida Fernández, Puc-Chile, Chile Veneza Mayora Ronsini, Universidade Federal de Santa Maria, Brasil Vera Regina Veiga França, Universidade Federal de Minas Gerais, Brasil

\section{COMISSÃO EDITORIAL}

Cristiane Freitas Gutfreind I Pontifícia Universidade Católica do Rio Grande do Sul, Brasil Irene Machado I Universidade de São Paulo, Brasil

Jorge Cardoso Filho I Universidade Federal do Reconcavo da Bahia, Brasil / Universidade Federal da Bahia, Brasil

CONSULTORES AD HOC

Adriana Amaral, Universidade do Vale do Rio dos Sinos, Brasil

Alexandre Rocha da Silva, Universidade Federal do Rio Grande do Sul, Brasi Arthur Ituassu, Pontifícia Universidade Católica do Rio de Janeiro, Brasil Bruno Souza Leal, Universidade Federal de Minas Gerais, Brasil Elizabeth Bastos Duarte, Universidade Federal de Santa Maria, Brasil Francisco Paulo Jamil Marques, Universidade Federal do Ceará, Brasi Maurício Lissovsky, Universidade Federal do Rio de Janeiro, Brasil Suzana Kilpp, Universidade do Vale do Rio dos Sinos, Brasil Vander Casaqui, Escola Superior de Propaganda e Marketing, Brasil

EDIÇÃO DE TEXTO E RESUMOS I Susane Barros SECRETÁRIA EXECUTIVA I Helena Stigger EDITORAÇÃo ELETRÔNICA I Roka Estúdio
COMPÓS I www.compos.org.br

Associação Nacional dos Programas de Pós-Graduação em Comunicação

Presidente

Eduardo Morettin

Universidade de São Paulo, Brasil

eduardomorettin@usp.br

Vice-presidente

Inês Vitorino

Universidade Federal do Ceará, Brasil

ines@ufc.br

Secretária-Geral

Gislene da Silva

Universidade Federal de Santa Catarina, Brasil

gislenedasilva@gmail.com 